\title{
Chronic ethanol exposure produces tolerance to elevations in neuroactive steroids: Mechanisms and reversal by exogenous ACTH
}

\author{
Kevin N. Boyd ${ }^{\star}, \dagger$, Sandeep Kumar ${ }^{\dagger} \ddagger$, Todd K. O'Buckley ${ }^{\dagger}$, and A. Leslie Morrow ${ }^{\star}, \dagger, \ddagger, \S$ \\ ${ }^{*}$ Curriculum in Toxicology, School of Medicine, University of North Carolina at Chapel Hill, Chapel \\ Hill, North Carolina, USA \\ †Bowles Center for Alcohol Studies, School of Medicine, University of North Carolina at Chapel \\ Hill, Chapel Hill, North Carolina, USA \\ FDepartment of Psychiatry, School of Medicine, University of North Carolina at Chapel Hill, \\ Chapel Hill, North Carolina, USA \\ §Department of Pharmacology, School of Medicine, University of North Carolina at Chapel Hill, \\ Chapel Hill, North Carolina, USA
}

\begin{abstract}
Acute ethanol administration increases potent GABAergic neuroactive steroids, specifically ( $3 \alpha$, $5 \alpha)$-3-hydroxypregnan-20-one ( $3 \alpha, 5 \alpha$-THP) and ( $3 \alpha, 5 \alpha)$-3,21-dihydroxypregnan-20-one. In addition, neuroactive steroids contribute to ethanol actions. Chronic ethanol exposure results in tolerance to many effects of ethanol, including ethanol-induced increases in neuroactive steroid levels. To determine the mechanisms of tolerance to ethanol-induced increases in neuroactive steroids, we investigated critical signaling molecules that are required for acute ethanol effects. Male Sprague-Dawley rats were administered ethanol via liquid diet for 2 weeks and steroid levels, adrenocorticotrophic hormone (ACTH) and adrenal steroidogenic acute regulatory (StAR) protein expression were measured. Chronic ethanol exposure elicits tolerance to ethanol-induced elevation of serum ACTH and the steroids pregnenolone and progesterone. Surprisingly, chronic ethanol exposure does not result in tolerance to ethanol-induced increases in adrenal StAR protein. However, ethanol-induced StAR phosphorylation is decreased when compared to acute ethanol administration. A separate group of rats exposed to chronic ethanol diet were subsequently challenged with ethanol $(2 \mathrm{~g} / \mathrm{kg})$ and exhibited a blunted elevation of serum ACTH and progesterone as well as cerebral cortical and hippocampal $3 \alpha, 5 \alpha$-THP. Administration of ACTH with the ethanol challenge restored the elevation of serum ACTH and progesterone as well as cerebral cortical $3 \alpha, 5 \alpha$-THP levels to those observed in ethanol-naïve rats. Thus, chronic ethanol exposure disrupts ACTH release, which results in tolerance to ethanol-induced increases in neuroactive steroid levels. Loss of the ethanol-induced increases in neuroactive steroids may contribute to behavioral tolerance to ethanol and influence the progression towards alcoholism.
\end{abstract}

\section{Keywords}

ACTH; adrenal; brain; ethanol; GABA; neuro-active steroid 
Neuroactive steroids produce their effects on membrane receptors that regulate central nervous system activity rather than on nuclear receptors that regulate gene expression. Thus, these steroids are capable of eliciting rapid changes in neuronal excitability, primarily through their enhancement of $\mathrm{GABA}_{\mathrm{A}}$ receptor activity (for review, see Belelli and Lambert 2005). Neuroactive steroids can be synthesized de novo in the brain or produced peripherally in the adrenals and gonads. Potent GABAergic neuroactive steroids $(3 \alpha, 5 \alpha)-3-$


modulate $\mathrm{GABA}_{\mathrm{A}}$ receptor activity (Majewska et al. 1986) and can elicit many of the same behavioral effects as ethanol (see Morrow 2007, for review).

Systemic ethanol administration increases serum and brain levels of neuroactive steroids that contribute to several of the behavioral effects of ethanol. In fact, administration of steroid biosynthetic enzyme inhibitors or adrenalectomy inhibits or completely blocks specific ethanol actions. Indeed, GABAergic neuroactive steroids contribute to ethanol's inhibitory actions on medial septal neurons (VanDoren et al. 2000), as well as antidepressant-like actions (Hirani et al. 2002), anxiolytic (Hirani et al. 2005), anticonvulsant (VanDoren et al. 2000), hypnotic effects (Khisti et al. 2003b) and spatial learning deficits (Matthews et al. 2002). Furthermore, the GABA agonist-like steroids substitute for ethanol in discrimination studies in rodents and monkeys (Grant et al. 1996) and their exogenous administration can alter ethanol drinking patterns (Janak et al. 1998; Finn et al. 1997; Ford et al. 2007; Morrow et al. 2003). Thus, determining how GABAergic neuroactive steroids are synthesized and regulated following ethanol administration is important for understanding various ethanol actions.

It has long been known that adrenocorticotrophic hormone (ACTH) release is important for adrenal stimulation (Rivier et al. 1984), and acute ethanol administration activates the hypothalamic-pituitary-adrenal (HPA) axis to increase the stress hormone corticosterone in rodents (for review, see Rivier 1996). We have recently shown that ethanol-induced increases in neuroactive steroids in both serum and brain following acute ethanol administration are dependent upon pituitary ACTH release, de novo adrenal steroidogenic acute regulatory (StAR) protein synthesis and cytochrome P450 side chain cleavage enzyme activity (Boyd et al. 2010). Indeed, disruptions or alterations in HPA axis signaling markedly affect neuroactive steroid levels, and studies involving adrenalectomized animals have demonstrated the necessity of the adrenals for ethanol-induced increases in serum and brain neuroactive steroids (Khisti et al. 2003b; O'Dell et al. 2004).

Although activation of the HPA axis is important for steroidogenesis, the rate-limiting step is the transfer of cholesterol from the outer mitochondrial membrane to cytochrome P450 side chain cleavage enzyme residing on the inner mitochondrial membrane (Miller 1988). Cholesterol cannot pass freely across the mitochondrial membranes and must be assisted by protein transport via StAR in the adrenals. Acute ethanol administration has been shown to increase adrenal StAR protein concomitantly with serum steroid levels (Khisti et al. 2003a), and we recently demonstrated that de novo adrenal StAR synthesis is essential for ethanolinduced increases in serum and brain neuroactive steroids (Boyd et al. 2010). In addition, a knockout of the StAR gene is lethal in mice (Caron et al. 1997), and mutations in humans disrupt steroid production causing congenital lipoid adrenal hyperplasia (Lin et al. 1995), further demonstrating its importance.

Chronic ethanol exposure results in a number of adaptive changes in central nervous system activity leading to tolerance to the behavioral effects of ethanol (Khanna et al. 1991; Kalant 1998). While chronic ethanol exposure does not affect basal levels of neuroactive steroids, tolerance develops to ethanol-induced increases in steroid levels (Janis et al. 1998), and the effect of subsequent ethanol challenge on cortical $3 \alpha, 5 \alpha$-THP levels is blunted (Morrow et 
al. 2001). In addition, adrenalectomized rodents have reduced levels of neuroactive steroids, exhibit tolerance to the sedative-hypnotic effects of ethanol (Khisti et al. 2003b) and display increased ethanol withdrawal severity (Gililland and Finn 2007).

Because behavioral effects of ethanol are partially dependent on ethanol-induced steroidogenesis, the loss of this effect following chronic ethanol exposure may contribute to ethanol tolerance. Focusing on the mechanisms of steroido-genesis recently found to be critical for increases in neuroactive steroids following acute ethanol administration, the present study investigated the mechanisms that underlie tolerance to ethanol-induced increases in neuroactive steroids resulting from chronic ethanol exposure. Tolerance to ethanol-induced increases in neuroactive steroids may alter ethanol sensitivity and contribute to risk for alcoholism and alcohol use disorders.

\section{Materials and methods}

\section{Animals}

Male Sprague-Dawley rats weighing between $225 \mathrm{~g}$ and $350 \mathrm{~g}$ were used for all experiments (Harlan, Indianapolis, IN, USA). The animals were group housed (three per cage) and maintained in 12-h light and dark (lights on, 7:00 Ам to 7:00 Рм) conditions with food and water available ad libitum. Rats were acclimated to handling for 1 week before the test day. All experiments were conducted in accordance with the guidelines of the National Institutes of Health Guide for the Care and Use of Laboratory Animals and approved by the Institutional Animal Care and Use Committee of the University of North Carolina at Chapel Hill.

\section{Chronic ethanol liquid diet administration}

Rats were housed individually and administered a nutritionally complete liquid diet for the first 3 days (Custom Stanley Diet, MP Biomedicals, Costa Mesa, CA, USA). Rats then received ethanol $(6 \% \mathrm{v} / \mathrm{v})$ in liquid diet for 7 days, followed by an increase to $7.5 \%$ ethanol for the duration of the study. Control rats were fed the identical diet with dextrose substituted isocalorically for ethanol. Water was available ad libitum and dietary consumption was monitored daily (the rats consumed $8-10 \mathrm{~g} / \mathrm{kg} /$ day). The mean body weights for the controls and ethanol diet rats were similar at the termination of the experiment. This procedure reliably results in physical dependence on ethanol (Morrow et al. 1992). Ethanol dependent rats had free access to ethanol diet up until the time of killing.

Separate groups of rats that consumed ethanol by liquid diet for 14 days were injected with a challenge dose of ethanol ( $2 \mathrm{~g} / \mathrm{kg}, 20 \% \mathrm{v} / \mathrm{v}$ in saline, i.p.) and tissue was collected after 60 $\mathrm{min}$. These rats were denied access to ethanol and fed standard chow for $24 \mathrm{~h}$ prior to the ethanol challenge. Rats receiving exogenous ACTH were administered two doses of ACTH $(2 \mu \mathrm{g}$, i.p.), one concurrently with the saline or ethanol challenge and one 30 min later. Tissue was collected $60 \mathrm{~min}$ after the saline or ethanol challenge. All rats were habituated to saline injections and were killed by decapitation. Blood alcohol levels were measured from $6 \mu \mathrm{L}$ aliquots of serum using a SRI 8610c gas chromatograph (Torrance, CA, USA) as previously described (Boyd et al. 2008).

\section{Tissue and protein preparations}

Mitochondrial membrane fractions from adrenal glands were prepared by homogenization, low speed centrifugation in $0.32 \mathrm{M}$ sucrose and centrifugation of the supernatant at $17000 \mathrm{~g}$ for $30 \mathrm{~min}$. The pellet (mitochondrial fraction) was resuspended in phosphate-buffered saline. Individual cerebral cortices, as well as other brain regions, were homogenized 
directly in $2 \%$ sodium dodecyl sulfate (SDS). Protein measurement was conducted using a BCA protein assay (Thermo Fisher Scientific Inc, Rockford, IL, USA).

\section{Western blot analysis}

Adrenal mitochondrial fractions and cerebral cortical homogenate were subjected to SDSpolyacrylamide gel electrophoresis (SDS-PAGE) using Novex Tris-Glycine gels (8-16\%), transferred to polyvinylidene diflouride membranes (Invitrogen, Carlsbad, CA, USA) and probed with StAR antibody (1:1000) (Abcam, Cambridge, MA, USA). Blots were subsequently exposed to a second primary antibody directed against $\beta$-actin $(1: 1000)$ (Millipore, Bilerica, MA, USA) to verify equivalent protein loading and transfer. Bands were detected by enhanced chemiluminescence (GE Healthcare, Piscataway, NJ, USA), apposed to $\mathrm{x}$-ray films under non-saturating conditions and analyzed by densitometric measurements using NIH Image 1.57. All comparisons were made within blots and statistical analysis was conducted using Student's $t$-test or one-way anova.

\section{Phospho-protein kinase A substrate immunoprecipitation analysis}

Protein in the mitochondrial fraction was immunoprecipitated with phospho-protein kinase A (PKA) substrate antibody (Cell Signaling Technology Inc., Danvers, MA, USA) as previously described (Kumar et al. 2002). Briefly, mitochondrial protein (200 $\mu \mathrm{g})$ was solubilized and denatured in radioimmunoprecipitation assay buffer (Sigma-Aldrich, St. Louis, MO, USA) with phosphatase inhibitor cocktail (Sigma-Aldrich), phenylmethylsulfonyl fluoride $(1 \mathrm{mM})$, sodium fluoride $(50 \mathrm{mM})$, sodium vanadate (200 $\mu \mathrm{M})$ and EDTA $(2 \mathrm{mM})$ to prevent protein degradation and dephosphorylation. This fraction was centrifuged at $10000 \mathrm{~g}$ and supernatant (solubilized protein) was collected.

Denaturation of protein in the supernatant was confirmed by SDS-PAGE analysis.

Immunoprecipitation of phosphoproteins for detection of phospho-StAR was performed using antibody conjugated to Dynal beads (Invitrogen) and western blot analysis of the immunoprecipitate. The optimal antibody and protein concentrations for immunoprecipitation were determined in pilot experiments to optimize the conditions. The phospho-PKA substrate specific antibody (Rockland Inc., Gilbertsville, PA, USA) was linked to Dynal beads by incubating $125 \mu \mathrm{L}$ of Dynal beads with $100 \mu \mathrm{L}$ of antibody $(0.35$ $\mu \mathrm{g} / \mu \mathrm{L}$ ) for $1 \mathrm{~h}$ at $22-24^{\circ} \mathrm{C}$. The solubilized receptors were mixed with antibody-linked beads in a final volume of $500 \mu \mathrm{L}$ and incubated on an orbital shaker overnight at $4^{\circ} \mathrm{C}$. The receptor-antibody-bead complex was washed three times with phosphate-buffered saline, resuspended in $50 \mu \mathrm{L}$ of SDS and boiled for $5 \mathrm{~min}$. Phosphoprotein immunoprecipitates and adrenal mitochondrial fractions were subsequently analyzed by SDS-PAGE gel electrophoresis and western blotting to examine the effects of ethanol exposure on phosphoStAR protein and total StAR protein.

\section{Radioimmunoassay of neuroactive steroid $3 \alpha, 5 \alpha-$ THP}

Radioimmunoassays (RIAs) were conducted as previously described (Janis et al. 1998). Briefly, brain samples were weighed and suspended in $2.5 \mathrm{~mL}$ of $0.3 \mathrm{~N} \mathrm{NaOH}$, homogenized with a sonic dismembrator and extracted three times with $3 \mathrm{~mL}$ aliquots of $10 \%$ ethyl acetate in heptane (v/v). Extraction recovery was monitored by the addition of $2000 \mathrm{cpm}$ of $\left[{ }^{3} \mathrm{H}\right] 3 \alpha, 5 \alpha$-THP (PerkinElmer, Waltham, MA, USA). The brain extracts were purified using solid phase silica columns (Burdick and Jackson, Muskegon, MI, USA) and subsequently dried. Samples were reconstituted and assayed in duplicate by the addition of $\left[{ }^{3} \mathrm{H}\right] 3 \alpha, 5 \alpha$-THP and polyclonal sheep anti-3 $3,5 \alpha-$ THP antibody (Obtained from Dr. Robert Purdy, Scripps Research Institute). Total binding was determined in the absence of unlabeled $3 \alpha, 5 \alpha$-THP and non-specific binding was determined in the absence of antibody. The antibody binding reaction was allowed to equilibrate for $2 \mathrm{~h}$ and cold dextran coated 
charcoal was used to separate bound from unbound steroid. Bound radioactivity was determined by liquid scintillation spectroscopy. Steroid levels in the samples were extrapolated from a concurrently run standard curve and corrected for their respective extraction efficiencies. The inter-assay coefficient of variation was $9.1 \%$ and the intra-assay coefficient of variation is $2.2 \%$. The $3 \alpha, 5 \alpha$-THP antibody has minimal cross-reactivity with other circulating steroids (Janis et al. 1998). $3 \alpha, 5 \alpha$-THP antiserum cross-reacts with progesterone $<3 \%, 3 \alpha, 5 \beta$-THP $6.6 \%, 3 \beta, 5 \alpha$-THP $2.8 \%, 3 \beta, 5 \beta$-THP $0.5 \%$, $5 \alpha$-pregnan- $3 \alpha$, $20 \alpha$-diol $0.1 \%$ and $5 \alpha$-pregnan-3,20-dione $3.5 \%$. The antiserum cross-reacts with $(3 \alpha)$-3hydroxy-4-pregnen-20-one $>100 \%$. This steroid is also a potent modulator of $\mathrm{GABA}_{\mathrm{A}}$ receptors (Morrow et al. 1990) and has been found at comparable levels to $3 \alpha, 5 \alpha-\mathrm{THP}$ in serum (Wiebe et al. 1994), but at markedly lower levels than $3 \alpha, 5 \alpha$-THP in cerebral cortex (Griffin and Mellon 2001).

\section{RIA of steroid precursor pregnenolone}

Pregnenolone levels were measured by RIA, as previously described (Porcu et al. 2006). Briefly, pregnenolone was extracted from $250 \mu \mathrm{L}$ of serum with $2 \mathrm{~mL}$ of diethyl ether three times. Extraction recovery was monitored by the addition of $1000 \mathrm{cpm}$ of $\left[{ }^{3} \mathrm{H}\right]$ pregnenolone (MP Biomedicals). Samples were reconstituted and assayed in duplicate by the addition of $\left[{ }^{3} \mathrm{H}\right]$ pregnenolone and anti-pregnenolone antibody (MP Biomedicals). Total binding was determined in the absence of unlabeled pregnenolone and non-specific binding was determined in the absence of antibody. The antibody binding reaction was allowed to equilibrate for a minimum of $4 \mathrm{~h}$ and cold dextran coated charcoal was used to separate bound from unbound steroid. Bound radioactivity was determined by liquid scintillation spectroscopy. Steroid levels in the samples were extrapolated from a concurrently run standard curve and corrected for their respective extraction efficiencies. The antiserum

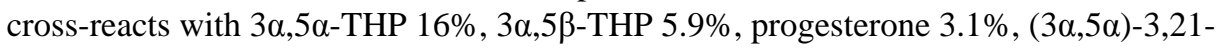
dihydroxypregnan-20-one $1.1 \%$. All of the following steroids had less than $1 \%$ crossreactivity: 5 $\alpha$-dihydroprogesterone, $17 \alpha$-hydroxyprogesterone, deoxycorticosterone, cortisol, 11-deoxycortisol, corticosterone, androsterone, $5 \alpha$-dihydrotestosterone, cholesterol, 17 $\beta$ estradiol, estrone and estriol. The intra-assay and inter-assay coefficients of variation were $7.71 \%$ and $5.93 \%$, respectively.

\section{RIA of progesterone and ACTH}

Serum progesterone and ACTH levels were measured using RIA kits according to the manufacturer's instructions (MP Biomedicals). Trunk blood was collected and spun down at $1730 \mathrm{~g}$ for $15 \mathrm{~min}$ at $4^{\circ} \mathrm{C}$ to obtain serum, and $\mathrm{ACTH}$ and progesterone levels were measured on the day of tissue collection. Total binding was determined in the absence of unlabeled progesterone or ACTH, and non-specific binding was determined in the absence of antibody. Steroid levels in the samples were extrapolated from a concurrently run standard curve. The intra-assay and inter-assay coefficients of variation for progesterone are $3.6 \%$ and $6.7 \%$ and for $\mathrm{ACTH}$ are $4.1 \%$ and $3.9 \%$, respectively.

\section{Data analysis}

Results are expressed as mean \pm SEM. Steroid levels are expressed as $n g / g$ for brain tissue and $\mathrm{ng} / \mathrm{mL}$ for serum. Western blot data were normalized to $\beta$-actin signals from the same blot and expressed as \% control values taken from each blot. Significance was determined by anova followed by post-hoc tests or the Student's $t$-test as appropriate. Analyses were performed using the software GraphPad Prism version 4 (GraphPad Software, San Diego, CA, USA). 


\section{Results}

\section{Neuroactive steroids are not increased after chronic ethanol exposure}

To determine if chronic ethanol exposure for 2 weeks elicits changes in steroid biosynthesis we first measured levels of the neuroactive steroid precursors. Rats were chronically exposed to ethanol through a nutritionally complete liquid diet and serum steroid levels were measured. Following chronic ethanol administration, there were no changes in serum ACTH, pregnenolone or progesterone (Fig. 1a-c) compared to pair-fed control rats. Our lab has previously shown that there are also no increases in serum or cerebral cortical $3 \alpha, 5 \alpha-$ THP in dependent rats (Janis et al. 1998).

\section{Chronic ethanol exposure blunts the neuroactive steroid response to an ethanol challenge}

Next, we investigated the steroid response to an ethanol challenge $(2 \mathrm{~g} / \mathrm{kg}$, i.p.) in rats chronically exposed to ethanol for 2 weeks and withdrawn for $24 \mathrm{~h}$. We challenged the rats with $2 \mathrm{~g} / \mathrm{kg}$ ethanol because previous studies demonstrated that $2 \mathrm{~g} / \mathrm{kg}$ produced a maximal effect on neuroactive steroid levels (VanDoren et al. 2000; Boyd et al. 2010). In the group of rats administered control diet, ethanol challenge resulted in increased serum ACTH levels compared to rats administered a saline challenge. However, rats exposed to chronic ethanol in their diet exhibited reduced serum ACTH levels compared to the control diet group challenged with ethanol, and no change in serum ACTH levels compared to rats fed control diet and challenged with saline $[F(3,31)=6.92, p=0.0011$; Fig. 2a]. Furthermore, the ethanol challenge of rats exposed to chronic ethanol did not significantly alter serum ACTH compared to chronic ethanol exposed rats administered a saline challenge. These rats also showed similar results for serum progesterone levels $[F(3,15)=27.28, p<0.0001 ;$ Fig. 2b], as well as cerebral cortical $3 \alpha, 5 \alpha$-THP levels $[F(3,14)=14.2, p=0.0002$; Fig. $2 c]$. Indeed, ethanol administration to rats administered control diet increased steroid levels in serum and brain that were lost following chronic ethanol exposure. Ethanol challenge resulted in a blunted steroid response in both serum and brain that was not significantly different from the effect of saline challenge in the chronic ethanol-exposed group. Importantly, there does not appear to be any effect of the control diet on ACTH or steroid levels, and rats in the control diet group respond to the $2 \mathrm{~g} / \mathrm{kg}$ ethanol challenge similarly to a naïve animal (Boyd et al. 2010). Finally, ethanol challenge produced similar blood alcohol concentrations in rats administered ethanol diet for 2 weeks $(223 \pm 6 \mathrm{mg} / \mathrm{dL}, n=21)$ versus ethanol naïve rats tested in our previous studies ( $237 \pm 8 \mathrm{mg} / \mathrm{dL}$, Khisti et al. 2003a); $166 \pm 12 \mathrm{mg} / \mathrm{dL}$ (Boyd et al. 2008); $257 \pm 6 \mathrm{mg} / \mathrm{dL}$ (Porcu et al. 2010), suggesting that metabolic tolerance did not contribute to the effects of chronic ethanol liquid diet exposure on neuroactive steroid levels.

\section{The importance of StAR protein phosphorylation for neuroactive steroid synthesis}

Because chronic ethanol exposed rats appeared to be tolerant to ethanol-induced increases in serum pregnenolone and progesterone, this suggested that adaptations must have occurred in adrenal steroid biosynthetic mechanisms. Thus, we investigated the effects of chronic ethanol exposure on the cholesterol transport protein StAR. Chronic ethanol administration increases adrenal StAR protein 3.26-fold compared to control diet $[t(22)=4.95, p<0.0001$; Fig. 3a]. This increase in adrenal StAR protein expression is similar to that observed following acute ethanol administration (Fig. 4). However, the $2 \mathrm{~g} / \mathrm{kg}$ ethanol challenge does not have any further effect on adrenal StAR protein compared to chronic ethanol-exposure and the saline challenge (Fig. 3b). Furthermore, while acute ethanol administration increases StAR phosphorylation $[t(6)=3.75, p=0.0096]$, chronic ethanol administration does not alter StAR phosphorylation compared to rats administered control diet, suggesting the development of tolerance to ethanol enhanced StAR phosphorylation (Fig. 4). 


\section{Restoration of ACTH levels restores neuroactive steroid levels following chronic ethanol exposure}

Because rats chronically exposed to ethanol appeared to be tolerant to increases in both ACTH and neuroactive steroid levels following an ethanol challenge, we examined if exogenous ACTH replacement could restore ethanol-induced steroidogenesis. Separate groups of rats were administered liquid diet as described above; however, in this experiment, all groups received ethanol diet, and we examined the effect of ACTH replacement with the saline or ethanol challenge. The ethanol challenge, in combination with exogenous ACTH administration, increased serum ACTH and progesterone, as well as cerebral cortical $3 \alpha, 5 \alpha-$ THP levels (Fig. 5a-c). Remarkably, ACTH restored the effect of ethanol on steroid levels to similar concentrations found in naïve animals administered ethanol (Boyd et al. 2010).

Chronic ethanol exposed rats administered saline and ACTH have elevated ACTH levels compared to ethanol exposed rats administered saline without ACTH. Moreover, chronic ethanol exposed rats challenged with ethanol and ACTH show increased serum ACTH compared to chronic ethanol exposed rats challenged with ethanol alone, as well as rats challenged with saline and ACTH $[F(3,29)=10.24, p<0.0001$; Fig. 5a]. These rats also showed similar results for serum progesterone levels $[F(3,30)=25.35, p<0.0001$; Fig. 5b] as well as cerebral cortical $3 \alpha, 5 \alpha$-THP levels $[F(3,30)=7.39, p=0.0008$; Fig. $5 \mathrm{c}]$. Indeed, serum progesterone and cerebral cortical $3 \alpha, 5 \alpha$-THP were greater in chronic ethanol exposed rats challenged with ethanol and ACTH compared to those challenged with ethanol alone, or those challenged with saline and ACTH.

As ACTH administration following chronic ethanol exposure in rats restored the ethanolinduced increases in serum and brain steroid levels, we also examined whether it reinstated the phosphorylation of StAR. Adrenals were used from the same rats as steroid measurements in Fig. 5 and results are presented as the fold increase of phosphorylated or total StAR for each group compared to chronic ethanol exposed rats administered a saline challenge. Chronic ethanol exposed rats receiving the ethanol challenge, saline + ACTH challenge, or ethanol $+\mathrm{ACTH}$ challenge, all exhibited increases in phosphorylated StAR protein $[F(5,28)=2.9, p=0.031 ;$ Fig. 6$]$. While post-hoc tests revealed no significant differences between groups, ethanol + ACTH increased StAR phosphorylation to a much greater extent than ethanol challenge alone, suggesting a possible trend. By comparison, total StAR was not elevated in any group, suggesting that the observed increases in phosphorylated StAR cannot be attributed to an increase in total StAR protein.

\section{Discussion}

Changes in $\mathrm{GABA}_{\mathrm{A}}$ receptor activity contribute to tolerance and dependence following prolonged exposure to ethanol (for review, see Kumar et al. 2009). The ethanol-induced increases in neuroactive steroids, which positively modulate $\mathrm{GABA}_{\mathrm{A}}$ receptor activity, were lost after chronic ethanol exposure. This loss of neuroactive steroid production may influence $\mathrm{GABA}_{\mathrm{A}}$ receptor function and contribute to tolerance to ethanol's effects. Results of the present study indicated that blunted ACTH levels, as well as the loss of StAR phosphorylation, following chronic ethanol exposure dramatically altered serum and brain neuroactive steroid levels. Importantly, exogenous ACTH completely restored the neuroactive steroid response in serum and brain, which suggested that these are important mechanisms altered by chronic ethanol exposure.

Hypothalamic-pituitary-adrenal axis activity is important for steroidogenesis and CNS functions as dysregulation of the HPA axis has been shown to be associated with altered steroid responses as well as depression and various other mood disorders (McQuade and Young 2000). When the HPA axis is functioning properly, steroids, including GABAergic 
neuroactive steroids, are increased by HPA axis activation, but also provide negative feedback to inhibit corticotropin releasing factor (CRF) production and release, ACTH release and corticosterone levels in rodents (for review, see Morrow et al. 2006). In the present study, the blunted steroid response observed after chronic ethanol exposure appears to be related to dysregulation of the HPA axis, as we also observed blunted ACTH levels following chronic ethanol exposure. Indeed, ACTH stimulation of adrenal function is essential for steroidogenesis as well as adrenal integrity. In fact, the tolerance to increased ACTH levels was concomitant with tolerance to increased neuroactive steroid levels observed following chronic ethanol exposure. These results are congruent with previous data where hypophysectomized rats displayed atrophied adrenals characterized by reduced weight and less steroidogenic output (Colby et al. 1974; Boyd et al. 2010), which demonstrated the importance of ACTH signaling. Furthermore, the fact that tolerance to ethanol-induced increases in neuroactive steroids occurred in both serum and brain further exemplified the significance of HPA axis signaling and the adrenal for regulating both circulating and central levels of neuroactive steroids. It should be pointed out, however, that RIA may not be sensitive enough to detect localized changes in brain steroidogenesis (Sanna et al. 2004). Therefore, the effect of chronic ethanol exposure on localized synthesis of neuroactive steroids is still unknown.

Ethanol-induced elevations of pregnenolone, progesterone and $3 \alpha, 5 \alpha$-THP were all blunted after chronic ethanol exposure, which suggested that alterations occurred early in the steroidogenic pathway. StAR, which mediates cholesterol transport required for steroidogenesis, was increased by acute ethanol administration and correlated with increased steroid levels (Khisti et al. 2003a). Because steroid levels were blunted following chronic ethanol exposure, we hypothesized that we would also observe changes in StAR protein expression. Conversely, adrenal StAR protein remained elevated following chronic ethanol exposure. However, tolerance to ethanol-induced phosphorylation of StAR was observed after chronic ethanol exposure and may contribute to reduced StAR activity indicated by the reduced levels of serum pregnenolone.

Alterations in ACTH following chronic ethanol exposure may explain the blunted neuroactive steroid responses directly, because of adrenal stimulation, and indirectly, through phosphorylation of StAR. Indeed, ACTH increases cAMP, and previous studies have demonstrated the importance of PKA phosphorylation for the activity of StAR (Arakane et al. 1997). Furthermore, experiments in Leydig cells demonstrated that protein kinase $\mathrm{C}$ activation could elicit increases in StAR protein expression, but protein kinase $\mathrm{C}$ did not increase steroid levels or phosphorylate StAR. However, addition of a cAMP analogue increased StAR phosphorylation and steroid levels (Jo et al. 2005). Thus, increases in StAR protein expression do not promote steroidogenesis if StAR is not phosphorylated.

In the present study, exogenous ACTH administration to dependent rats restored the ethanolinduced steroid response, which suggested that ACTH was critical. Although StAR was still increased following chronic ethanol exposure, steroid levels were blunted without exogenous ACTH administration. However, chronic ethanol exposed rats challenged with ethanol still showed increases in phosphorylated StAR despite the blunted ACTH release. This suggests that ACTH is not the only factor controlling the phosphorylation of StAR and that ethanol may stimulate StAR phosphorylation via another mechanism. Nevertheless, when exogenous ACTH was administered with an ethanol challenge, the full steroidogenic response was restored. Thus, following chronic ethanol exposure, increases in adrenal StAR protein expression and StAR phosphorylation are not sufficient for maximal steroidogenesis.

Although the present study did not explore effects of chronic ethanol exposure on HPA axis function upstream of ACTH, these effects likely regulate ACTH release. Indeed, knocking- 
out the type $1 \mathrm{CRF}$ receptor in mice blunted the ACTH response to ethanol, and repeated alcohol exposure blunted CRF and type $1 \mathrm{CRF}$ receptor activity as well as ACTH response (Lee et al. 2001b,a). However, regardless of where proper functioning is altered, blunted ACTH release is an important consequence of chronic ethanol exposure. Following repeated ethanol exposure to rats, the ACTH response to an acute ethanol challenge has been shown to remain blunted for at least 21 days, which would correspond to over 1 year in humans (Rivier and Lee 2001). Interestingly, in a subsequent study, the blunting of the ACTH response to acute ethanol challenge was not permanent (Lee and Rivier 2003). However, if a short duration of repeated ethanol exposure alters ACTH function for an extended period of time, then prolonged ethanol dependence might cause more pronounced, or even permanent, effects. Furthermore, after repeated exposure to a stimulus such as ethanol, the HPA axis does not respond to the same stimulus, but remains capable of mounting a full response to different stimuli (Rivier and Lee 2001). This result suggests that the HPA axis is extremely complex, as ethanol is specific in blunting the axis response to future ethanol exposures while, at the same time, maintaining full HPA axis activation to new stressors. Perhaps ethanol is targeting extrahypothalamic mechanisms to initiate HPA axis activity.

Different laboratories employ various paradigms for chronic ethanol administration with differences in lengths and routes of exposure. Our method of 2 weeks of ethanol in a liquid diet reliably results in physical dependence on ethanol (Morrow et al. 1992). In addition, extending the ethanol diet out to 6 weeks produced the same effect in terms of blunted ACTH and steroid levels (unpublished result). Moreover, when dependent rats were challenged with a $2 \mathrm{~g} / \mathrm{kg}$ dose of ethanol they no longer responded like naïve animals, which suggested ethanol tolerance. ACTH and neuroactive steroid levels were blunted whether we challenged the animal on the 15th day of liquid diet administration or $24 \mathrm{~h}$ following ethanol withdrawal. Similar alterations in neuroactive steroid levels have been seen in other chronic models where the loss of neuroactive steroid production was linked to behavioral effects such as increased anxiety and seizure susceptibility (Cagetti et al. 2004).

Because neuroactive steroids contribute to many of the effects of ethanol, tolerance to ethanol-induced increases in neuroactive steroids may lead to increased consumption of alcohol. Indeed, chronic ethanol exposed rats that no longer have elevated $3 \alpha, 5 \alpha$-THP levels readily self-administer ethanol, but this can be reduced by $3 \alpha, 5 \alpha$-THP administration (Morrow et al. 2001). Conversely, 3 $3,5 \alpha$-THP appears to be rewarding in non-dependent rats (Janak et al. 1998), hence tolerance to increased steroid levels may promote greater drinking to achieve the same pharmacological effects. These ideas remain speculative, however, and further studies are needed to determine the role of endogenous neuroactive steroids in ethanol drinking behavior.

Because neuroactive steroids appear to contribute to ethanol sensitivity (Morrow 2007; Morrow and Porcu 2009), and HPA axis activation contributes to steroidogenesis, it is reasonable to suggest that proper HPA axis functioning plays a role in ethanol sensitivity. In fact, clinical studies have shown a link between alcoholism and alterations in HPA axis functioning (Adinoff et al. 2005; Lovallo et al. 2000). In rats, it has been suggested that the loss of elevated ACTH and steroid responses following chronic drinking are more important than low basal hormone levels for the escalation of drinking. In addition, the opioid antagonist naltrexone, which has been shown to reduce relapse risk in human alcoholics, activates the HPA axis and increases ACTH and steroid levels (O'Malley et al. 2002). Furthermore, naltrexone selectively increases serum $3 \alpha, 5 \alpha$-THP in heavy drinkers that harbor the mu opiate receptor polymorphism (Ray et al. 2010), a single nucleotide polymorphism marker that has been associated with improved treatment response in several studies (Oslin et al. 2003; Anton et al. 2008). Naltrexone has also been shown to reverse the suppression of testosterone observed after chronic ethanol exposure (Emanuele et al. 1999). 
Moreover, serum levels of the HPA antagonist leptin are elevated in human alcoholics, correlated with ethanol consumption (Nicolas et al. 2001), and leptin injections in mice increase alcohol intake (Kiefer et al. 2001). Furthermore, leptin decreases the expression of StAR in adrenocortical cells and inhibits steroid synthesis (Cherradi et al. 2001). Together, all of these results are consistent with the present study and suggest a link between HPA axis activity, StAR protein, neuroactive steroids and ethanol consumption.

We conclude that pituitary ACTH along with adrenal StAR protein activity are critical for ethanol-induced increases in neuroactive steroids. Chronic ethanol exposure alters the HPA axis and blunts both ACTH and steroid responses to subsequent ethanol challenges, and these phenomena contribute to ethanol tolerance and dependence. The findings of the present study suggest that ACTH depletion may contribute to ethanol tolerance and dependence as well as promote associated withdrawal symptoms and continued excessive drinking.

\section{Acknowledgments}

This work was supported by R37-AA10564 (ALM) and T32-AA007573. We thank Patrizia Porcu, Ph.D. for helpful comments on the manuscript.

\section{Abbreviations used}

3a,5a-THP

ACTH

CRF

HPA

PKA

RIA

SDS

SDS-PAGE

StAR

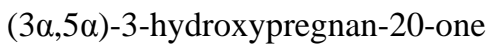

adrenocorticotrophic hormone

corticotropin releasing factor

hypothalamic-pituitary-adrenal

protein kinase $\mathrm{A}$

radioimmunoassay

sodium dodecyl sulfate

SDS-polyacrylamide gel electrophoresis

steroidogenic acute regulatory protein

\section{References}

Adinoff B, Junghanns K, Kiefer F, Krishnan-Sarin S. Suppression of the HPA axis stress-response: implications for relapse. Alcohol. Clin. Exp. Res 2005;29:1351-1355. [PubMed: 16088999]

Anton RF, Oroszi G, O'Malley S, Couper D, Swift R, Pettinati H, Goldman D. An evaluation of muopioid receptor (OPRM1) as a predictor of naltrexone response in the treatment of alcohol dependence: results from the Combined Pharmacotherapies and Behavioral Interventions for Alcohol Dependence (COMBINE) study. Arch. Gen. Psychiatry 2008;65:135-144. [PubMed: 18250251]

Arakane F, King SR, Du Y, Kallen CB, Walsh LP, Watari H, Stocco DM, Strauss JF III. Phosphorylation of steroidogenic acute regulatory protein (StAR) modulates its steroidogenic activity. J. Biol. Chem 1997;272:32656-32662. [PubMed: 9405483]

Belelli D, Lambert JJ. Neurosteroids: endogenous regulators of the $\mathrm{GABA}_{\mathrm{A}}$ receptor. Nat. Rev. Neurosci 2005;6:565-575. [PubMed: 15959466]

Boyd KN, O'Buckley TK, Morrow AL. Role of acetaldehyde in ethanol-induced elevation of the neuroactive steroid 3 $\alpha$-hydroxy-5 $\alpha$-pregnan-20-one in rats. Alcohol. Clin. Exp. Res 2008;32:17741781. [PubMed: 18652594] 
Boyd KN, Kumar S, O'Buckley TK, Porcu P, Morrow AL. Ethanol induction of steroidogenesis in rat adrenal and brain is dependent upon pituitary ACTH release and de novo adrenal StAR synthesis. J. Neurochem 2010;112:784-796. [PubMed: 20021565]

Cagetti E, Pinna G, Guidotti A, Baicy K, Olsen RW. Chronic intermittent ethanol (CIE) administration in rats decreases levels of neurosteroids in hippocampus, accompanied by altered behavioral responses to neurosteroids and memory function. Neuropharmacology 2004;46:570-579. [PubMed: 14975681]

Caron KM, Soo SC, Wetsel WC, Stocco DM, Clark BJ, Parker KL. Targeted disruption of the mouse gene encoding steroidogenic acute regulatory protein provides insights into congenital lipoid adrenal hyperplasia. Proc. Natl Acad. Sci. USA 1997;94:11540-11545. [PubMed: 9326645]

Cherradi N, Capponi AM, Gaillard RC, Pralong FP. Decreased expression of steroidogenic acute regulatory protein: a novel mechanism participating in the leptin-induced inhibition of glucocorticoid biosynthesis. Endocrinology 2001;142:3302-3308. [PubMed: 11459771]

Colby HD, Malendowicz LK, Caffrey JL, Kitay JI. Effects of hypophysectomy and ACTH on adrenocortical function in the rat. Endocrinology 1974;94:1346-1350. [PubMed: 4362968]

Emanuele NV, LaPaglia N, Steiner J, Kirsteins L, Emanuele MA. Reversal of chronic ethanol-induced testosterone suppression in peripubertal male rats by opiate blockade. Alcohol. Clin. Exp. Res 1999;23:60-66. [PubMed: 10029204]

Finn DA, Phillips TJ, Okorn DM, Chester JA, Cunningham CL. Rewarding effect of the neuroactive steroid 3 $\alpha$-hydroxy- $\alpha$-pregnan-20-one in mice. Pharmacol. Biochem. Behav 1997;56:261-264. [PubMed: 9050083]

Ford MM, Mark GP, Nickel JD, Phillips TJ, Finn DA. Allopregnanolone influences the consummatory processes that govern ethanol drinking in C57BL/6J mice. Behav. Brain Res 2007;179:265-272. [PubMed: 17376546]

Gililland KR, Finn DA. The impact of gonadectomy and adrenalectomy on acute withdrawal severity in male and female C57BL/6J and DBA/2J mice following a single high dose of ethanol. Alcohol. Clin. Exp. Res 2007;31:1846-1857. [PubMed: 17850218]

Grant KA, Azarov A, Bowen CA, Mirkis S, Purdy RH. Ethanol-like discriminative stimulus effects of the neurosteroid $3 \alpha$-hydroxy-5 $\alpha$-pregnan-20-one in female Macaca fascicularis monkeys. Psychopharmacology 1996;124:340-346. [PubMed: 8739549]

Griffin LD, Mellon SH. Biosynthesis of the neurosteroid 3 alpha-hydroxy-4-pregnen-20-one (3 alpha hp), a specific inhibitor of FSH release. Endocrinology 2001;142:4617-4622. [PubMed: 11606426]

Hirani K, Khisti RT, Chopde CT. Behavioral action of ethanol in Porsolt's forced swim test: modulation by $3 \alpha$-hydroxy-5 $\alpha$-pregnan-20-one. Neuropharmacology 2002;43:1339-1350. [PubMed: 12527484]

Hirani K, Sharma AN, Jain NS, Ugale RR, Chopde CT. Evaluation of GABAergic neuroactive steroid $3 \alpha$-hydroxy-5 $\alpha$-pregnane-20-one as a neurobiological substrate for the anti-anxiety effect of ethanol in rats. Psychopharmacology 2005;180:267-278. [PubMed: 15719223]

Janak PH, Redfern JEM, Samson HH. The reinforcing effects of ethanol are altered by the endogenous neurosteroid, allopregnanolone. Alcohol. Clin. Exp. Res 1998;22:1106-1112. [PubMed: 9726282]

Janis GC, Devaud LL, Mitsuyama H, Morrow AL. Effects of chronic ethanol consumption and withdrawal on the neuroactive steroid $3 \alpha$-hydroxy-5 $\alpha$-pregnan-20-one in male and female rats. Alcohol. Clin. Exp. Res 1998;22:2055-2061. [PubMed: 9884151]

Jo Y, King SR, Khan SA, Stocco DM. Involvement of protein kinase C and cyclic adenosine 3', 5'monophosphate-dependent kinase in steroidogenic acute regulatory protein expression and steroid biosynthesis in leydig cells. Biol. Reprod 2005;73:244-255. [PubMed: 15814901]

Kalant H. Research on tolerance: what can we learn from history? Alcohol. Clin. Exp. Res 1998;22:67-76. [PubMed: 9514287]

Khanna JM, Kalant H, Shah G, Chau A. Tolerance to ethanol and cross-tolerance to pentobarbital and barbital in four rat strains. Pharmacol. Biochem. Behav 1991;39:705-709. [PubMed: 1784599]

Khisti RT, Kumar S, Morrow AL. Ethanol rapidly induces steroidogenic acute regulatory protein expression and translocation in rat adrenal gland. Eur. J. Pharmacol 2003a;473:225-227. [PubMed: 12892842] 
Khisti RT, VanDoren MJ, O'Buckley TK, Morrow AL. Neuroactive steroid 3 $\alpha$-hydroxy-5 $\alpha$ pregnan-20-one modulates ethanol-induced loss of righting reflex in rats. Brain Res 2003b; 980:255-265. [PubMed: 12867266]

Kiefer F, Jahn H, Wolf K, Kampf P, Knaudt K, Wiedemann K. Free-choice alcohol consumption in mice after application of the appetite regulating peptide leptin. Alcohol. Clin. Exp. Res 2001;25:787-789. [PubMed: 11371729]

Kumar S, Sieghart W, Morrow AL. Association of protein kinase $\mathrm{C}$ with $\mathrm{GABA}_{\mathrm{A}}$ receptors containing $\alpha 1$ and $\alpha 4$ subunits in the cerebral cortex: selective effects of chronic ethanol consumption. $\mathrm{J}$. Neurochem 2002;82:110-117. [PubMed: 12091471]

Kumar S, Porcu P, Werner DF, Matthews DB, Diaz-Granados JL, Helfand RS, Morrow AL. The role of $\mathrm{GABA}_{\mathrm{A}}$ receptors in the acute and chronic effects of ethanol: a decade of progress. Psychopharmacology (Berl) 2009;205:529-564. [PubMed: 19455309]

Lee S, Rivier C. Long-term influence of an initial exposure to alcohol on the rat hypothalamicpituitary axis. Alcohol. Clin. Exp. Res 2003;27:1463-1470. [PubMed: 14506408]

Lee S, Schmidt ED, Tilders FJ, Rivier C. Effect of repeated exposure to alcohol on the response of the hypothalamic-pituitary-adrenal axis of the rat: I. Role of changes in hypothalamic neuronal activity. Alcohol. Clin. Exp. Res 2001a;25:98-105. [PubMed: 11198721]

Lee S, Smith GW, Vale W, Lee KF, Rivier C. Mice that lack corticotropin-releasing factor (CRF) receptors type 1 show a blunted $\mathrm{ACTH}$ response to acute alcohol despite up-regulated constitutive hypothalamic CRF gene expression. Alcohol. Clin. Exp. Res 2001b;25:427-433. [PubMed: 11290855]

Lin D, Sugawara T, Strauss JF III, Clark BJ, Stocco DM, Saenger P, Rogol A, Miller WL. Role of steroidogenic acute regulatory protein in adrenal and gonadal steroidogenesis. Science 1995;267:1828-1831. [PubMed: 7892608]

Lovallo WR, Dickensheets SL, Myers DA, Thomas TL, Nixon SJ. Blunted stress cortisol response in abstinent alcoholic and polysubstance-abusing men. Alcohol. Clin. Exp. Res 2000;24:651-658. [PubMed: 10832906]

Majewska MD, Harrison NL, Schwartz RD, Barker JL, Paul SM. Steroid hormone metabolites are barbiturate-like modulators of the GABA receptor. Science 1986;232:1004-1007. [PubMed: 2422758]

Matthews DB, Morrow AL, Tokunaga S, McDaniel JR. Acute ethanol administration and acute allopregnanolone administration impair spatial memory in the Morris water task. Alcohol. Clin. Exp. Res 2002;26:1747-1751. [PubMed: 12436065]

McQuade R, Young AH. Future therapeutic targets in mood disorders: the glucocorticoid receptor. Br. J. Psychiatry 2000;177:390-395. [PubMed: 11059990]

Miller WL. Molecular biology of steroid hormone synthesis. Endoc. Rev 1988;9:295-318.

Morrow AL. Recent developments in the significance and therapeutic relevance of neuroactive steroids - Introduction to the special issue. Pharmacol. Ther 2007;116:1-6. [PubMed: 17531324]

Morrow, AL.; Porcu, P. Neuroactive steroid biomarkers of alcohol sensitivity and alcoholism risk. In: Ritsner, M., editor. Neuropsychiatric Bio-markers, Endophenotypes, and Genes. Springer Science + Business Media B.V.; Dordrecht: 2009. p. 47-57.

Morrow AL, Pace JR, Purdy RH, Paul SM. Characterization of steroid interactions with $\gamma$ aminobutyric acid receptor-gated chloride ion channels: evidence for multiple steroid recognition sites. Mol. Pharmacol 1990;37:263-270. [PubMed: 1689453]

Morrow AL, Herbert JS, Montpied P. Differential effects of chronic ethanol administration on $\mathrm{GABA}_{\mathrm{A}}$ receptor $\alpha 1$ and $\alpha 6$ subunit mRNA levels in rat cerebellum. Mol. Cell. Neurosci 1992;3:251-258. [PubMed: 19912867]

Morrow AL, VanDoren MJ, Penland SN, Matthews DB. The role of GABAergic neuroactive steroids in ethanol action, tolerance and dependence. Brain Res. Brain Res. Rev 2001;37:98-109. [PubMed: 11744078]

Morrow, AL.; Khisti, RT.; Tokunaga, S.; McDaniel, JR.; Matthews, DB. GABAergic neuroactive steroids modulate selective ethanol actions: mechanisms and significance. In: Smith, SH., editor. Neurosteroid Effects in the Central Nervous System: The Role of the GABA A Receptors. CRC Press; Miami: 2003. p. 219-245. 
Morrow AL, Porcu P, Boyd KN, Grant KA. Hypothalamic-pituitary-adrenal axis modulation of GABAergic neuro-active steroids influences ethanol sensitivity and drinking behavior. Dialogues Clin. Neurosci 2006;8:463-477. [PubMed: 17290803]

Nicolas JM, Fernandez-Sola J, Fatjo F, Casamitjana R, Bataller R, Sacanella E, Tobias E, Badia E, Estruch R. Increased circulating leptin levels in chronic alcoholism. Alcohol. Clin. Exp. Res 2001;25:83-88. [PubMed: 11198718]

O'Dell LE, Alomary AA, Vallee M, Koob GF, Fitzgerald RL, Purdy RH. Ethanol-induced increases in neuroactive steroids in the rat brain and plasma are absent in adrenalectomized and gonadectomized rats. Eur. J. Pharmacol 2004;484:241-247. [PubMed: 14744609]

O'Malley SS, Krishnan-Sarin S, Farren C, Sinha R, Kreek MJ. Naltrexone decreases craving and alcohol self-administration in alcohol-dependent subjects and activates the hypothalamo-pituitaryadrenocortical axis. Psychopharmacology (Berl) 2002;160:19-29. [PubMed: 11862370]

Oslin DW, Berrettini W, Kranzler HR, Pettinati H, Gelernter J, Volpicelli JR, O'Brien CP. A functional polymorphism of the mu-opioid receptor gene is associated with naltrexone response in alcohol-dependent patients. Neuropsychopharmacology 2003;28:1546-1552. [PubMed: 12813472]

Porcu P, Rogers LSM, Morrow AL, Grant KA. Plasma pregnenolone levels in cynomolgus monkeys following pharmacological challenges of the hypothalamic-pituitary-adrenal axis. Pharmacol. Biochem. Behav 2006;84:618-627. [PubMed: 16790266]

Porcu P, O'Buckley TK, Alward SE, Song SC, Grant KA, de Wit H, Morrow AL. Differential effects of ethanol on serum GABAergic $3 \alpha, 5 \alpha / 3 \alpha, 5 \beta$ neuroactive steroids in mice, rats, cynomolgus monkeys and humans. Alcohol. Clin. Exp. Res 2010;34:432-442. [PubMed: 20028362]

Ray LA, Hutchison KE, Ashenhurst JR, Morrow AL. Naltrexone selectively elevates GABAergic neuroactive steroid levels in heavy drinkers with the ASP40 allele of the OPRM1 gene: a pilot investigation. Alcohol. Clin. Exp. Res 2010;34:1-9. [PubMed: 19951289]

Rivier C. Alcohol stimulates ACTH secretion in the rat: mechanisms of action and interactions with other stimuli. Alcohol. Clin. Exp. Res 1996;20:240-254. [PubMed: 8730214]

Rivier C, Lee S. Effect of repeated exposure to alcohol on the response of the hypothalamic-pituitaryadrenal axis of the rat: II. Role of the length and regimen of alcohol treatment. Alcohol. Clin. Exp. Res 2001;25:106-111. [PubMed: 11198704]

Rivier C, Bruhn T, Vale W. Effect of ethanol on the hypothalamic-pituitary-adrenal axis in the rat: role of corticotropin-releasing factor (CRF). J. Pharmacol. Exp. Ther 1984;229:127-131. [PubMed: 6323684]

Sanna E, Talani G, Busonero F, Pisu MG, Purdy RH, Serra M, Biggio G. Brain steroidogenesis mediates ethanol modulation of $\mathrm{GABA}_{\mathrm{A}}$ receptor activity in rat hippocampus. J. Neurosci 2004;24:6521-6530. [PubMed: 15269263]

VanDoren MJ, Matthews DB, Janis GC, Grobin AC, Devaud LL, Morrow AL. Neuroactive steroid 3 $\alpha-$ hydroxy-5 $\alpha$-pregnan-20-one modulates electrophysiological and behavioral actions of ethanol. J. Neurosci 2000;20:1982-1989. [PubMed: 10684899]

Wiebe JP, De Gannes GC, Dallaire MJ. Synthesis of the allylic regulatory steroid, 3 alpha-hydroxy-4pregnen-20-one, by rat granulosa cells and its regulation by gonadotropins. Biol. Reprod 1994;50:956-964. [PubMed: 8199276] 

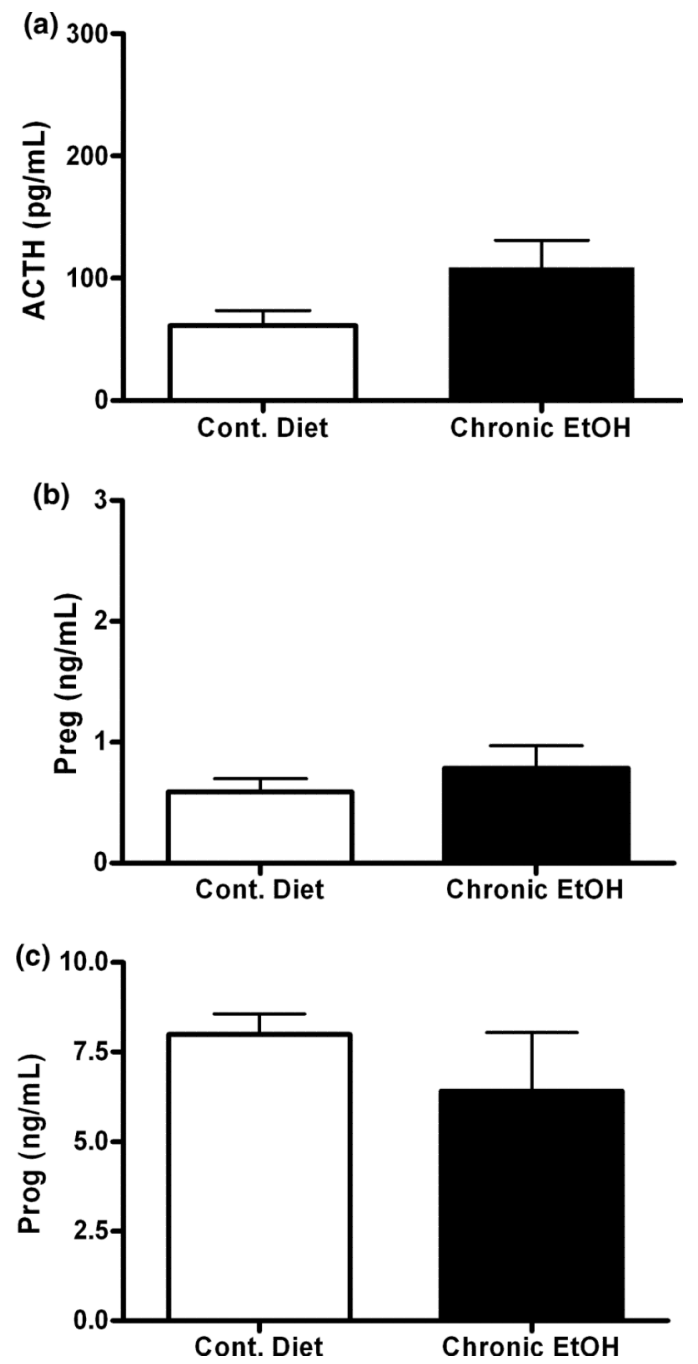

Fig. 1.

Chronic ethanol exposure does not elicit changes in ACTH, pregnenolone or progesterone. Chronic ethanol exposure was via liquid diet for 2 weeks and (a) ACTH, (b) pregnenolone and (c) progesterone were measured in serum. $n=8-10$ in duplicate. 


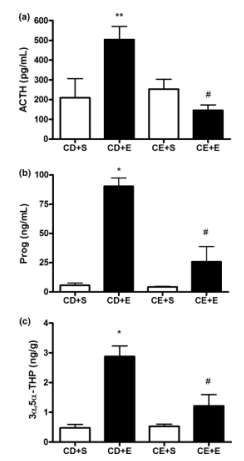

Fig. 2.

Chronic ethanol exposure elicits no change in ACTH levels but reduces the ACTH and steroid responses to ethanol challenge. Groups of rats administered control (CD) or ethanol (CE) diet for 2 weeks received a challenge injection of saline $(+S)$ or ethanol $(+E)(2 \mathrm{~g} / \mathrm{kg}$, i.p.), tissue was collected 60 min post-ethanol administration and serum (a) ACTH and (b) progesterone (Prog), as well as (c) cerebral cortical $3 \alpha, 5 \alpha$-THP were measured. $* p<0.001$ and ${ }^{* *} p<0.05$ compared to $\mathrm{CD}+\mathrm{S}$, and $\# p<0.01$ compared to $\mathrm{CD}+\mathrm{E}$ (Anova followed by Newman-Keuls test), $n=5-13$ in duplicate. 
(a)
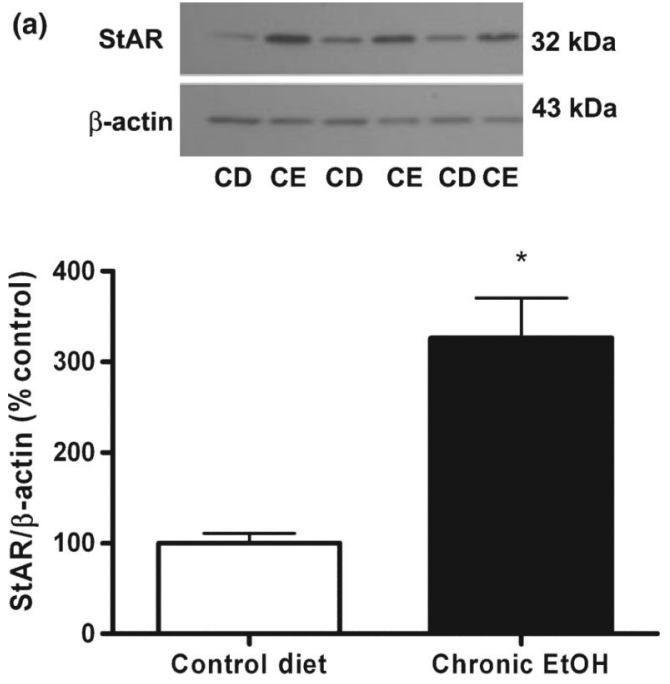

(b)
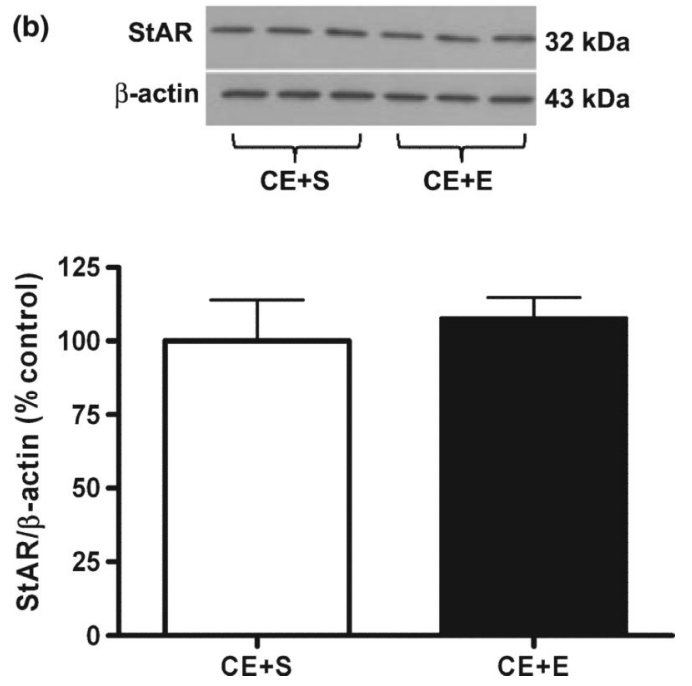

Fig. 3.

Adrenal StAR protein is elevated following chronic ethanol exposure but is not further increased by an ethanol challenge. (a) Adrenal StAR protein expression was measured via western blot analysis in rats exposed to liquid control (CD) and ethanol (CE) diet, normalized to $\beta$-actin and presented as \% control diet. (b) Adrenal StAR protein expression was also measured in separate groups of rats that were exposed to liquid ethanol diet and subsequently challenged with saline $(\mathrm{CE}+\mathrm{S})$ or ethanol $(2 \mathrm{~g} / \mathrm{kg})(\mathrm{CE}+\mathrm{E})$. Results are normalized to $\beta$-actin and presented as $\% \mathrm{CE}+\mathrm{S}$. Representative blots are shown above their respective bar graphs. ${ }^{*} p<0.0001$ compared to control diet (Student's $t$-test), $n=8-12$ in duplicate. 


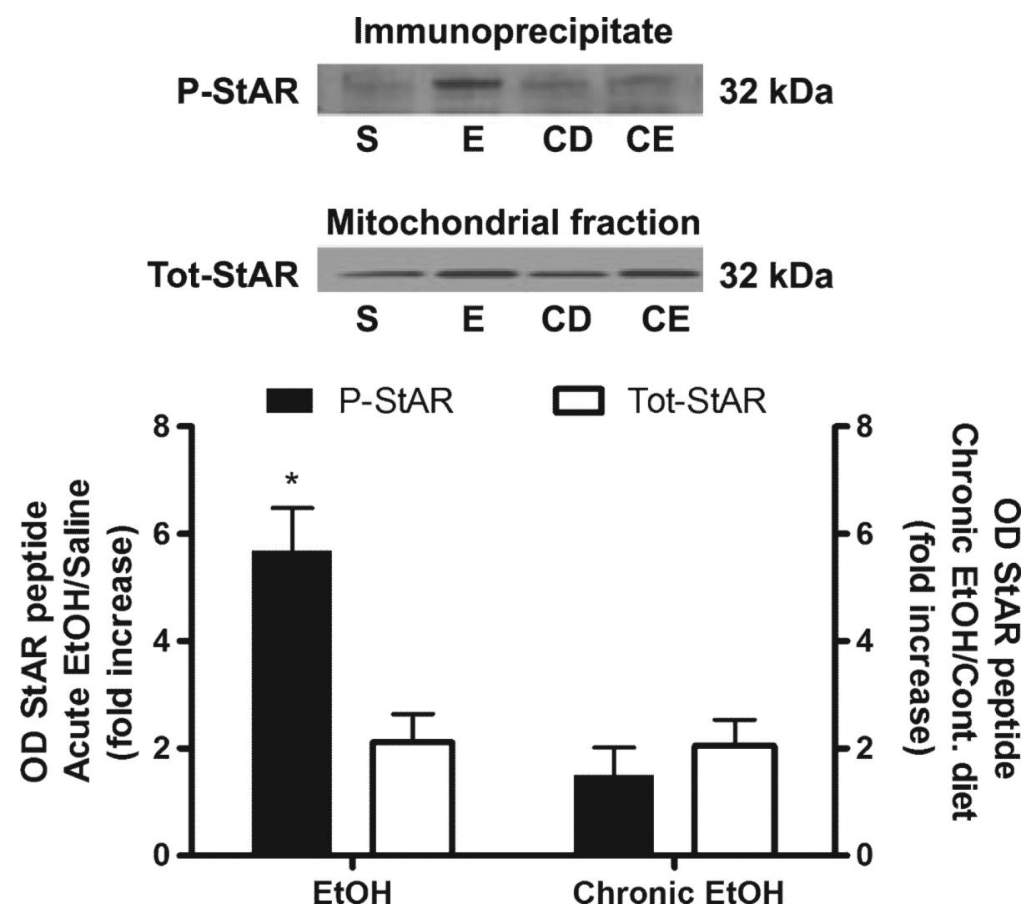

Fig. 4.

Chronic ethanol exposure results in tolerance to increased phosphorylation of adrenal StAR protein. Adrenal fractions were immunoprecipitated with phospho-PKA substrate antibody, separated by SDS-PAGE and probed with StAR. A representative blot is shown above the bar graph. For acute ethanol (E), results are reported as fold increase of phospho-StAR (PStAR) compared to saline (S). For chronic ethanol (CE) exposure, results are reported as fold increase of phospho-StAR compared to control diet (CD). The fold increase of total StAR (Tot-StAR) protein for both acute and chronic ethanol was also measured and compared to its respective control. * $p<0.01$ compared to total star for acute ethanol (Student's $t$-test), $n=4$. 

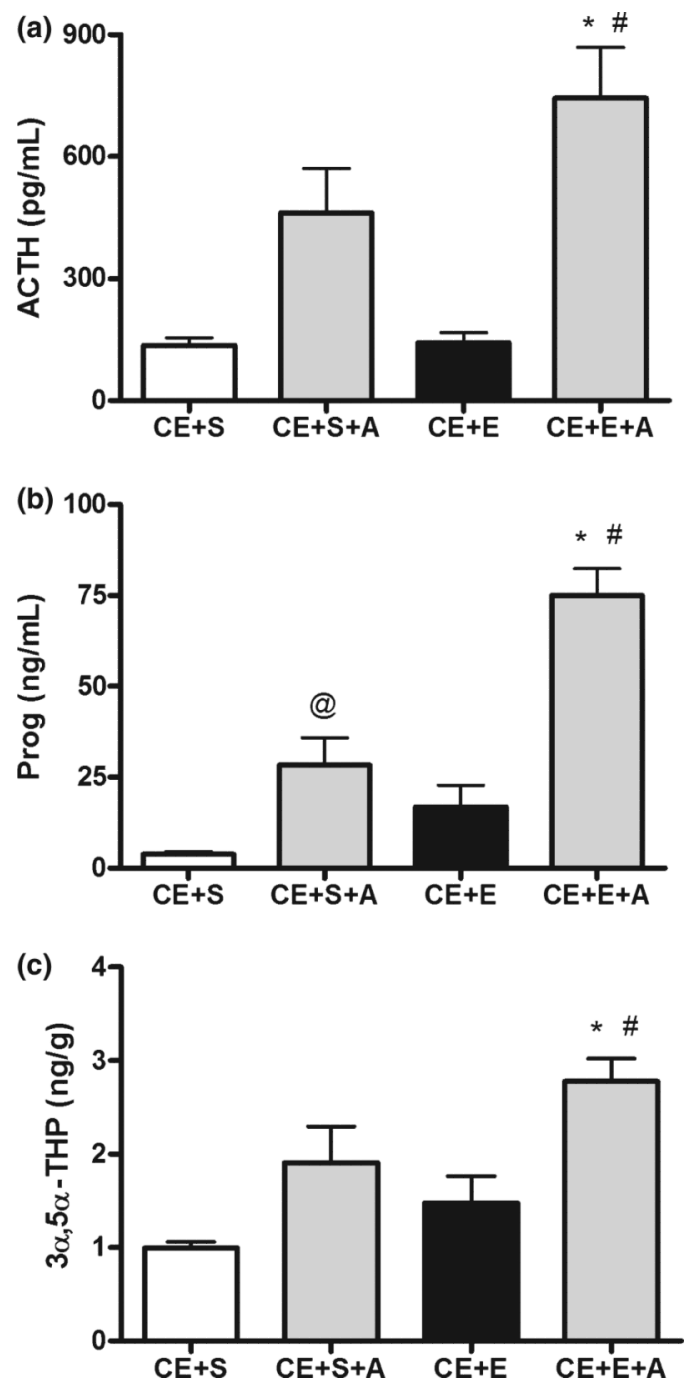

Fig. 5.

Exogenous ACTH replacement restores serum and brain neuroactive steroid levels following chronic ethanol exposure. Rats exposed to chronic dietary ethanol were challenged with saline or ethanol $(\mathrm{CE}+\mathrm{S}$ and $\mathrm{CE}+\mathrm{E}$, respectively). ACTH $(2 \mu \mathrm{g}$, i.p.) was administered along with the saline or ethanol challenge $(\mathrm{CE}+\mathrm{S}+\mathrm{A}$ and $\mathrm{CE}+\mathrm{E}+\mathrm{A}$, respectively). Tissues were collected $60 \mathrm{~min}$ after challenge and serum (a) ACTH and (b) progesterone, as well as (c) cerebral cortical $3 \alpha, 5 \alpha$-THP were measured. ${ }^{*} p<0.001$ compared to $\mathrm{CE}+\mathrm{S}, \# p<0.05$ compared to $\mathrm{CE}+\mathrm{S}+\mathrm{A}$ and $\mathrm{CE}+\mathrm{E}$, and @ $p<0.05$ compared to $\mathrm{CE}+\mathrm{S}$ (anova followed by Newman-Keuls test), $n=8-9$ in duplicate. 

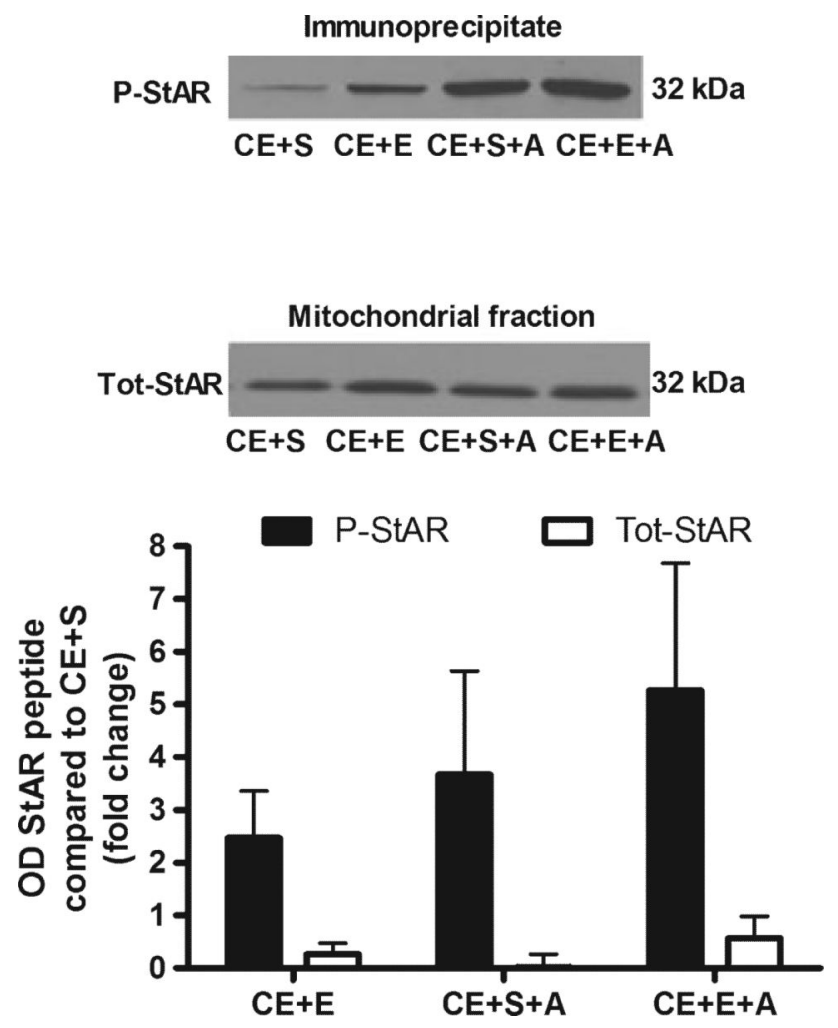

Fig. 6.

Phosphorylation of adrenal StAR protein is increased by ethanol and ACTH following chronic dietary ethanol exposure. Adrenal fractions were immunoprecipitated with phosphoPKA substrate antibody, separated by SDS-PAGE and probed with StAR antibody. A representative blot is shown above the bar graph (P-StAR, phospho-StAR; Tot-StAR, total StAR). Results are reported as the fold increase of phospho-StAR for each group compared to the chronic ethanol and saline $(\mathrm{CE}+\mathrm{S})$ group. Total StAR was also measured and reported as the fold increase for each group compared to the fold increase of total StAR for the $\mathrm{CE}+\mathrm{S}$ group. Chronic ethanol + ethanol $(\mathrm{CE}+\mathrm{E})$, chronic ethanol + saline $+\mathrm{ACTH}$ $(\mathrm{CE}+\mathrm{S}+\mathrm{A})$ and chronic ethanol + ethanol + ACTH $(\mathrm{CE}+\mathrm{E}+\mathrm{A}), n=6$. 